\title{
Obstetric and Neonatal Outcome of Induction of Labour at term with Sublingual Misoprostol as Compared to Intravaginal Misoprostol
}

\author{
Dr Raga Malika Devi Gontla ${ }^{1}$, Dr Shailaja Prasad ${ }^{2}$, Dr Anitha ${ }^{3}$, Dr Swetha \\ ${ }^{1,4}$ Post Graduate, Department of Obstetrics and Gynecology \\ ${ }^{2}$ Professor of Obstetrics and Gynecology \\ ${ }^{3}$ Assistant Professor of Obstetrics and Gynecology
}

\begin{abstract}
Background: Misoprostol, a synthetic prostaglandin E1 analog, has been given both orally and vaginally for induction of labor at term. Due to the difference in pharmacokinetics of sublingual as compared to vaginally administered misoprostol, hence this study.

Aim: To study Obstetric and Neonatal outcome of induction of labour with sublingual misoprostolas compared to intravaginal misoprostol.

Method: 120 women with singleton pregnancy with no Cephalo-pelvic disproportion were randomized to receive Tab. Misoprostol $25 \mathrm{mcg}$ at 4 hour interval by vaginal route (60 patients) and sublingual route (60 patients).

Results: With sublingual route of administration the number of doses of misoprostol used was significantly lower [ $p<0.05]$, reduced induction delivery interval [ $p<0.05]$, reduced pelvic examinations $[p<0.05]$ when compared to vaginal route of administration. No difference in maternal and foetal complications.
\end{abstract}

\section{Introduction}

Induction is defined as stimulation of contractions before the spontaneous onset of labor, with or without ruptured membranes. When the cervix is closed and uneffaced, labor induction commences with cervical ripening, a process that generally employs prostaglandins to soften and open the cervix ${ }^{1}$.Some centuries ago, fetal death was the only indication for labor induction. Now, in modern obstetrics, induction of labor at term in a live foetus with successful outcome is a challenge to obstetrician. Now-a-days the rate of labor induction varies in different centers. Despite a large body of literature, the optimal mode of induction for this purpose has yet to be established.

\section{Methods of Induction of Labor ${ }^{2}$}

a) Pharmacological- oxytocin, prostaglandins like PGE1 (misoprostol- tablet) and PGE2 (dinoprostone-gel, tablet and controlled release pessary), progesterone receptor antagonist-mifepristone.

b) Non-pharmacological- mechanical and surgical

$>$ Mechanical- mechanical dilators, foleys catheter (single balloon), trans cervical double balloon catheter, osmotic dilators, laminaria tents (natural) or dilapan (synthetic), extra amniotic saline infusion.

$>$ Surgical - sweeping of membranes and amniotomy (artificial rupture of membranes). 
There is no preferred method for induction and it depends on institute protocol.

There is increased risk of failed induction and caesarean section in presence of unfavorable cervix $^{3}$ and hence cervical ripening is needed.

\section{Aim of the Study}

To study obstetric and neonatal outcome of induction of labor at term with sublingual misoprostolas compared to intravaginal misoprostol.

\section{Objective of the Study}

To determine efficacy and safety of sublingual administration of misoprostol compared with vaginal misoprostol at or after term pregnancy in a women with a live foetus.

\section{Materials and Methods}

This study was conducted in Great Eastern Medical School and Hospital, Ragolu, Srikakulam, Andhra Pradesh in the department of obstetrics and Gynaecology during the period of December 2018 to June 2019 (6 months).

120 antenatal women admitted in the ward were included in this study.

\section{Inclusion Criteria}

1. Singleton pregnancy

2. Live foetus

3. Term gestation - 37 completed weeks or more with a medical or obstetric indication for induction including gestational age $>/ 41$ weeks (post dated pregnancy), prelabour rupture of membranes (PROM), gestational hypertension, mild pre eclampsia ,gestational diabetes mellitus (GDM) .

4. Primigravida and multiparous women

5. Cephalic presentation

6. An unfavourable cervix (bishop score $<5$ )

7. Reassuring foetal heart tracing.

\section{Exclusion Criteria}

1. Multiple gestation

2. Malpresentation (other than cephalic)

3. Previous uterine surgery (hysterotomy, myomectomy, caesarean section)
4. Contraindications for the use of prostaglandins like asthma

5. Grand multipara $(>5)$

6. Need for immediate delivery

7. Chorioamnionitis

8. Active Vaginal bleeding

9. Ultrasonically confirmed severe oligohydramnios, placenta praevia and macrosomia.

10. Abnormal doppler velocimetry

\section{Methodology}

Group A: Sublingual misoprostol [S]

60 patients for labour induction were randomly allocated for 25 microgram sublingual misoprostol administration every $4^{\text {th }}$ hourly for maximum of 6 doses.

Group B: vaginal misoprostol [V]

60 patients for labour induction were randomly allocated for 25 microgram vaginal misoprostol administration every $4^{\text {th }}$ hourly for maximum of 6 doses.

Further induction is withheld if women had regular contractions (3-4 contractions, lasting for more than 40 seconds in 10 minute duration, goes into active labor $(4 \mathrm{cms})$ or cervix is favourable for amniotomy (bishop score $>/ 8$ ). Oxytocin was adminsterd by diluting inringer lactate solution and started as IV drip ,not earlier than four hours of last dose of misoprostol.

Continuous fetal cardiotocography was used throughout the study.

All episodes of hyperstimulation were noted and included in study. Recognised episodes were managed by maternal repositioning, stopping the oxytocin infusion, maternal hydration and oxygenation. Women were advised to spit out the medication in sublingual group and in vaginal group tablet was removed from vagina if possible. Failure of induction is considered if women fails to enter active phase of labor following six doses of misoprostol through any route and it is considered as an indication for section. 
Results and Analysis

Table 1- Comparision of age (in years) and parity

\begin{tabular}{|c|c|c|}
\hline & Group A[S] & Group B [V] \\
\hline Age [years] & $25.07 \pm 3.97$ & $25.08 \pm 3.70$ \\
\hline Primi gravida & $42[70]$ & $43[71]$ \\
\hline Multigravida & $18[30]$ & $17[29]$ \\
\hline
\end{tabular}

Table 1 shows mean and standard deviation of age and parity in both groups. Primigravida and multigravida were shown in number [percentage]. No significant difference found in both groups.

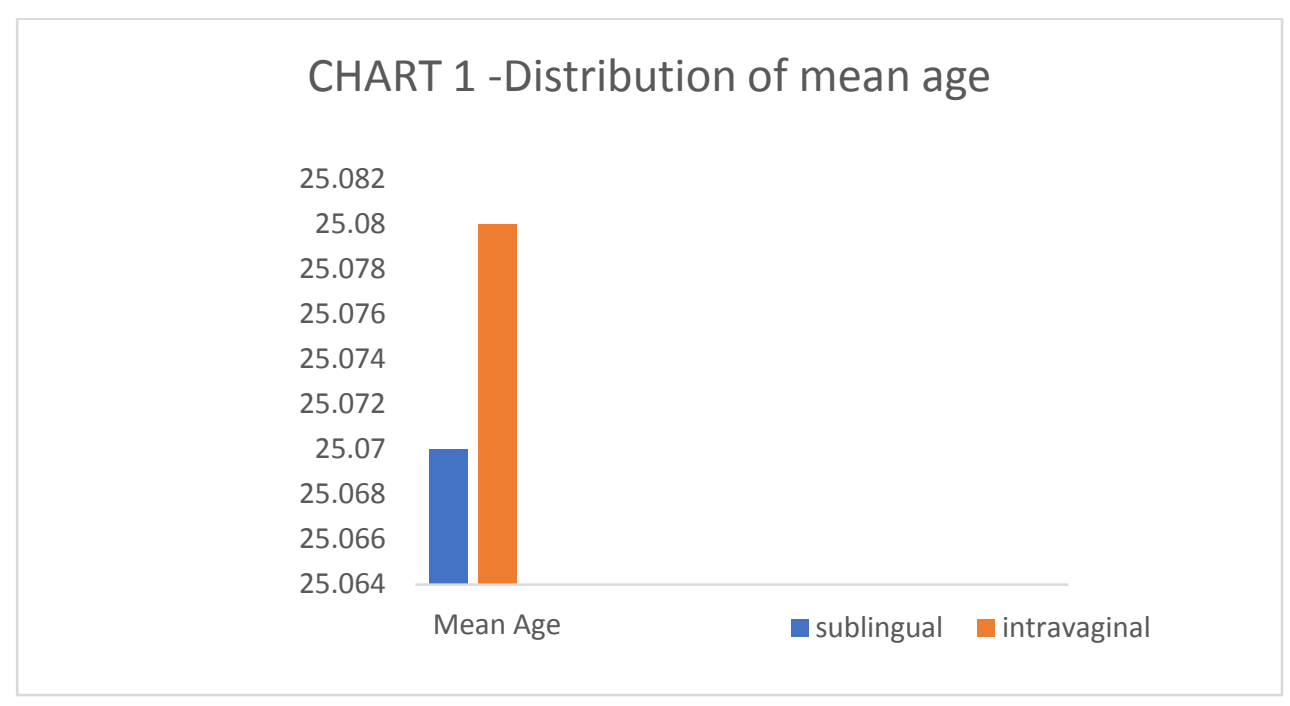

CHART 2 - Distribution of parity in sublingual group(group A) and intra vaginal(group B)

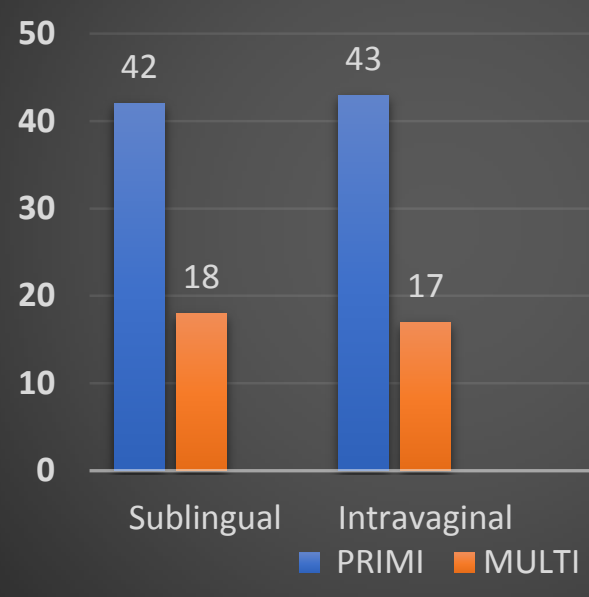

Table 2: Comparison of bishop score

\begin{tabular}{|c|c|c|c|}
\hline & Group A[S] & Group B [V] & P value \\
\hline Bishop score & $4.03 \pm 0.81$ & $4.05 \pm 0.59$ & 1.00 \\
\hline
\end{tabular}

Table 2 shows mean and standard deviation of significant difference among the groups. Bishop score in both groups. no There was no 


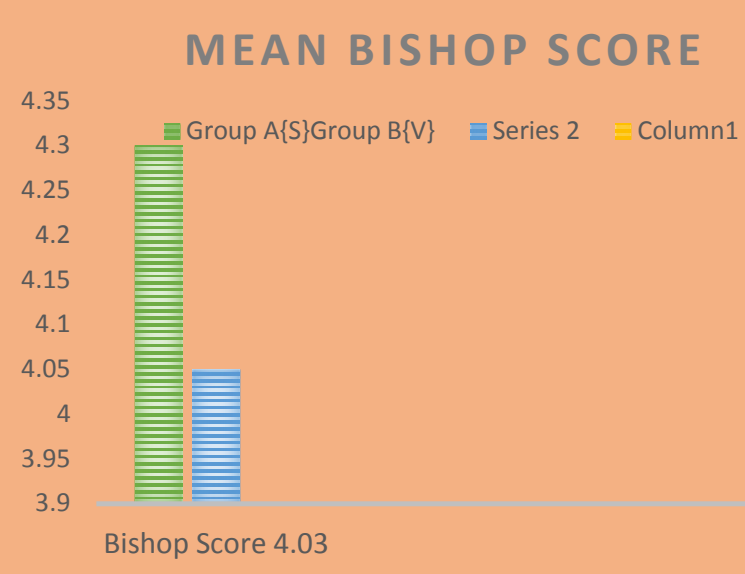

Table 3: Comparison of indication for induction

\begin{tabular}{|l|c|c|}
\hline & Group A[S] & Group B [V] \\
\hline Post term [>41 weeks] & $28[46.7]$ & $25[41.7]$ \\
\hline Prelabour rupture of membrame & $17[28.3]$ & $18[30]$ \\
\hline Mild preeclampsia & $11[18.3]$ & $14[23.3]$ \\
\hline Gestational diabetes mellitus & $4[6.7]$ & $3[5]$ \\
\hline
\end{tabular}

Table 5: Comparison of total doses of misoprostol

\begin{tabular}{|c|c|c|c|}
\hline & Group A[S] & Group B [V] & P value \\
\hline Total doses of misoprostol & $1.85 \pm 1.02$ & $2.3 \pm 1.2$ & $<0.05$ \\
\hline
\end{tabular}

Table 5 shows mean and standard deviation of Misoprostol used was significantly lower in total doses of misoprostol in both groups. sublingual route than vaginal route $[\mathrm{p}<0.05]$.

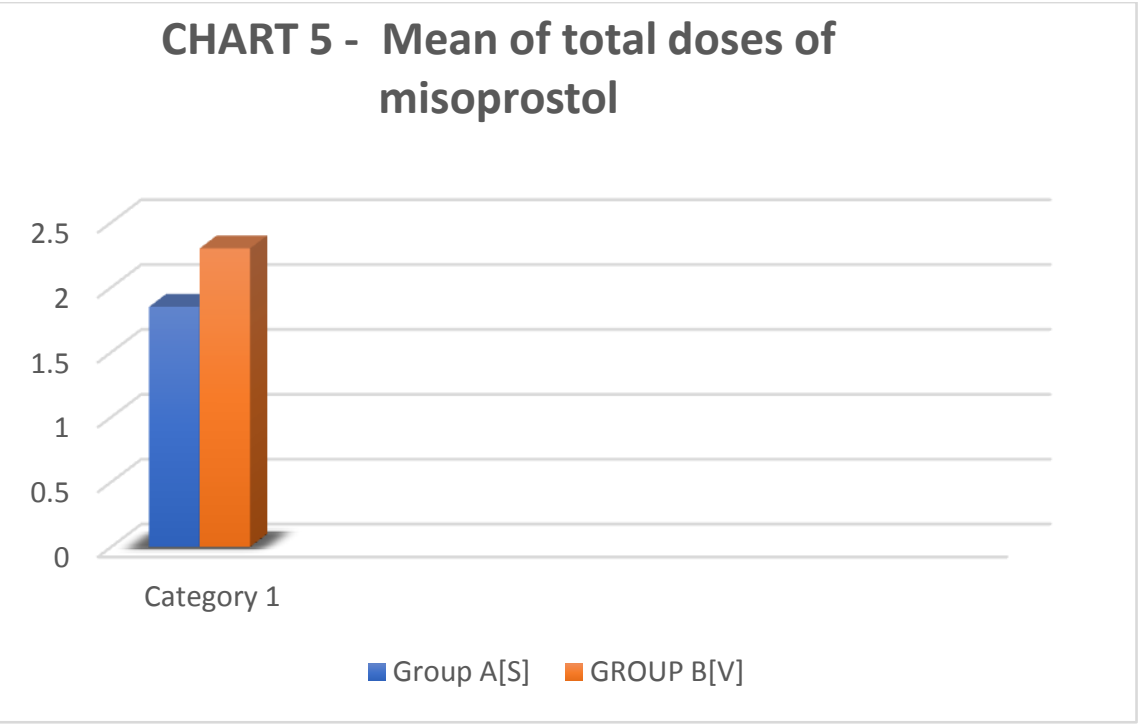

Table: 6 Comparison of number of vaginal examination

\begin{tabular}{|l|c|c|c|}
\hline & Group A[SLM] & Group B [VM] & P value \\
\hline mber of pelvic examination & $5.75 \pm 2.05$ & $8.22 \pm 2.04$ & $\mathrm{P}<0.05$ \\
\hline
\end{tabular}

Table 7 shows mean and standard deviation of number of pelvic examination in both groups. Pelvic examination was significantly lower in sublingual route misoprostol than vaginal route of administration $[\mathrm{p}<0.05]$. 


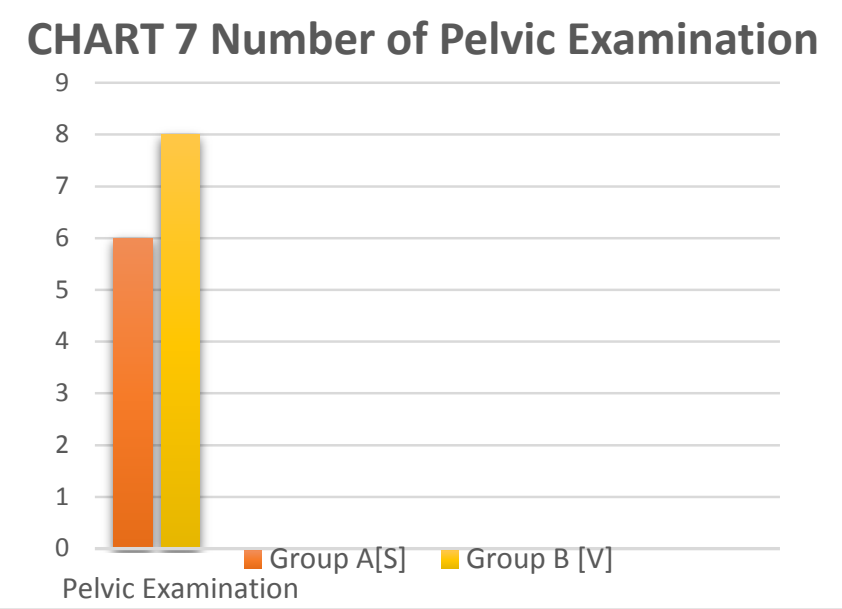

Table 8: Comparison of induction delivery interval [minutes]

\begin{tabular}{|l|c|c|c|}
\hline & Group A[SLM] & Group B [VM] & P value \\
\hline $\begin{array}{l}\text { Induction delivery } \\
\text { interval (min) }\end{array}$ & $650.98 \pm 250.83$ & $779.7 \pm 269.97$ & $\mathrm{P}<0.05$ \\
\hline $\begin{array}{l}\text { Induction vaginal } \\
\text { delivery interval (min) }\end{array}$ & $597.42 \pm 186.47$ & $720 \pm 195.47$ & $\mathrm{P}<0.005$ \\
\hline
\end{tabular}

Table 8 shows mean and standard deviation of induction delivery interval including caesarean section [minutes] and induction vaginal delivery interval [minutes] in both groups. Induction delivery interval including caesarean section and induction vaginal delivery interval was significantly lower in sublingual route misoprostol than vaginal route of administration $[\mathrm{p}<0.05]$

\section{Chart 8 Comparision of induction delivery interval}

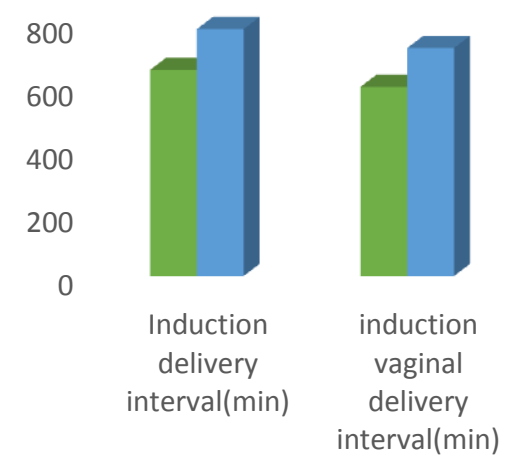

Table 9: Comparison of mode of delivery

\begin{tabular}{|c|c|c|c|}
\hline & Group A[SLM] & Group B [VM] & RR [CI 95\%] \\
\hline Spontaneous vaginal delivery & $49[81.7]$ & $45[75]$ & $1.09[0.90-1.32]$ \\
\hline Instrumental vaginal delivery & $3[5]$ & $5[8.3]$ & $0.6[0.15-2.40]$ \\
\hline Caesarean section & $8[13.3]$ & $10[16.7]$ & $0.8[0.34-1.89]$ \\
\hline
\end{tabular}

Table 9 shows number [percentage] of mode of difference among the groups. delivery in both groups. There was no significant 
Chart 9 Mode of Delivery
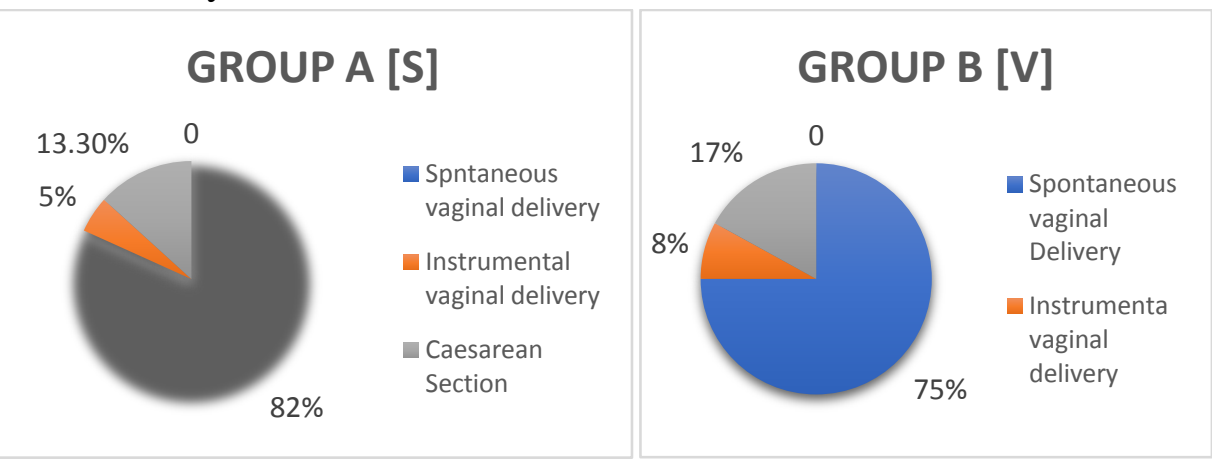

Table 10 Comparison of indication for caesarean section

\begin{tabular}{|l|c|c|c|}
\hline & Group A[SLM] & Group B [VM] & RR [CI 95\%] \\
\hline Fetal distress & $2[25]$ & $3[30]$ & $0.83[0.18-3.84]$ \\
\hline $\begin{array}{l}\text { Non progress of labour / arrest } \\
\text { of labour }\end{array}$ & $4[50]$ & $4[40]$ & $1.25[0.45-3.49]$ \\
\hline Failed induction & $2[25]$ & $3[30]$ & $0.83[0.18-3.84]$ \\
\hline
\end{tabular}

Table 10 shows number [percentage] of indication for caesarean section in both groups. There was no significant difference in fetal distress, non progress of labour / arrest of labour and failed induction among the groups.

Chart 10 Comparision for indication for induction
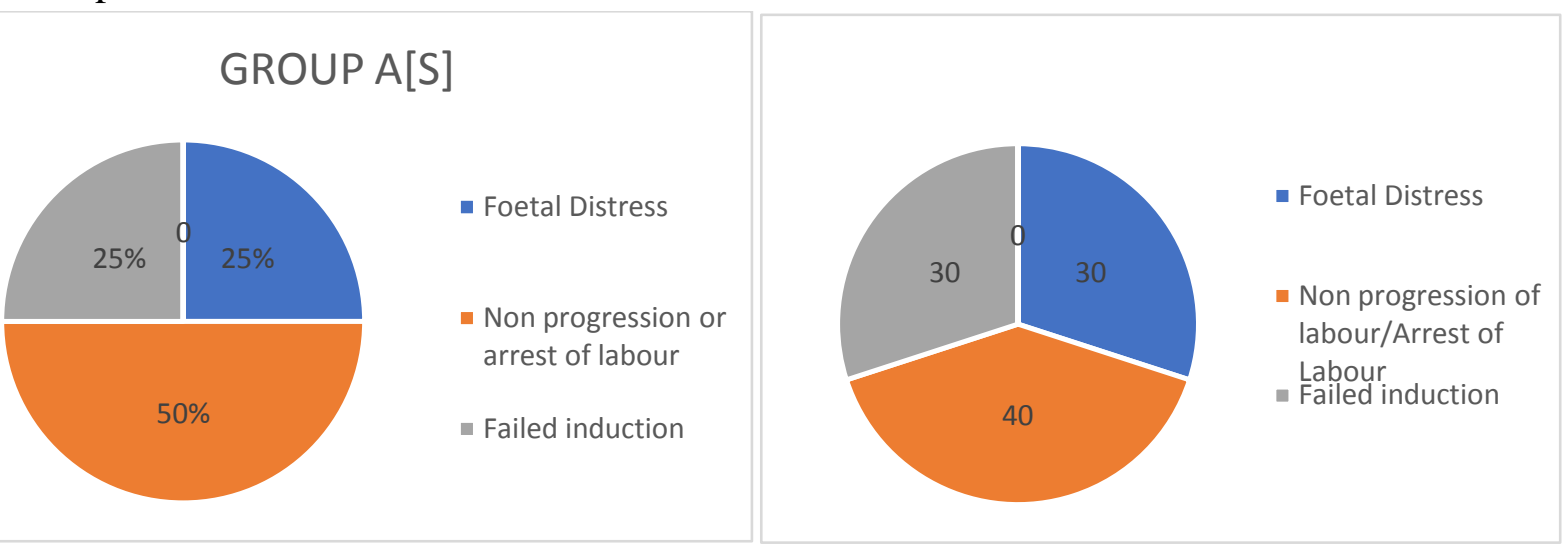

Chart 11 Comparison of maternal uterine complications

\begin{tabular}{|l|c|c|c|}
\hline & Group A[SLM] & Group B [VM] & RR [CI 95\%] \\
\hline Uterine Hyperstimulation & $3[5]$ & $2[3.3]$ & $1.5[0.26-8.66]$ \\
\hline
\end{tabular}

Table 12 shows number [percentage] of maternal significant difference among the groups. uterine complication in both groups. There was no 


\section{Chart 11}

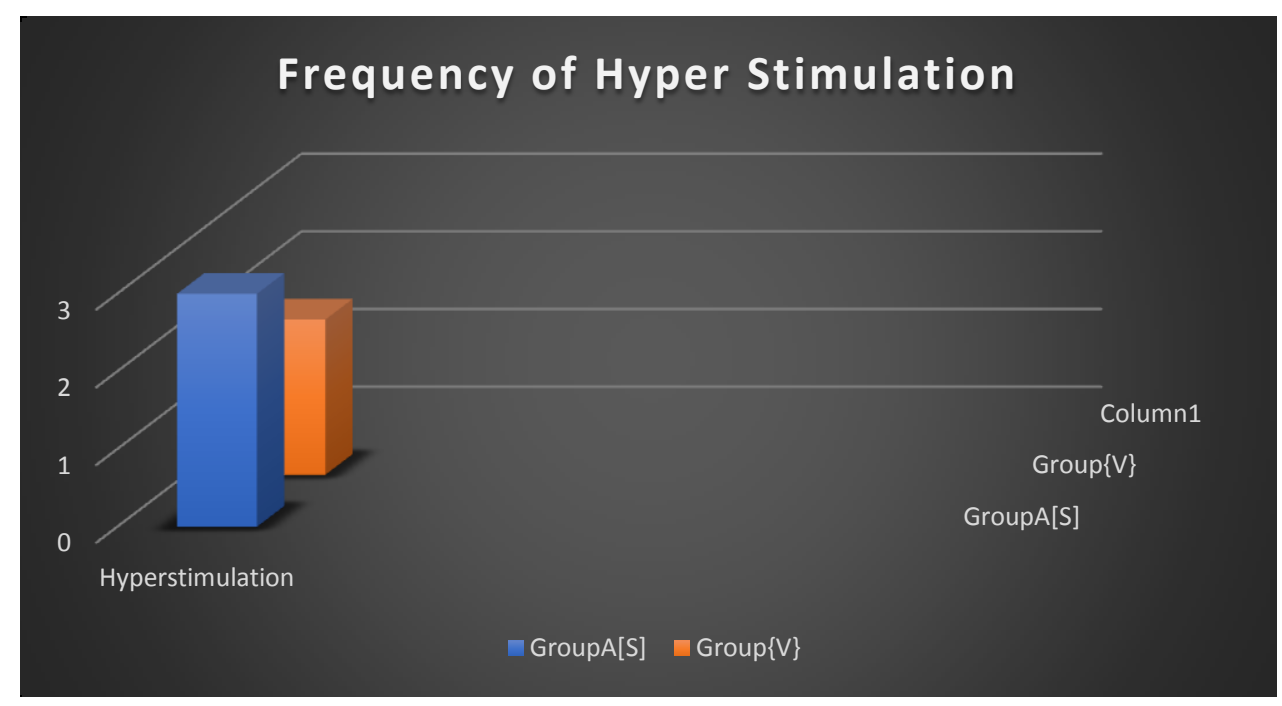

Table 4 shows number [percentage] of indication

significant difference among the group for induction in both groups. There was no

Chart 4 shows percentage of indication of induction.

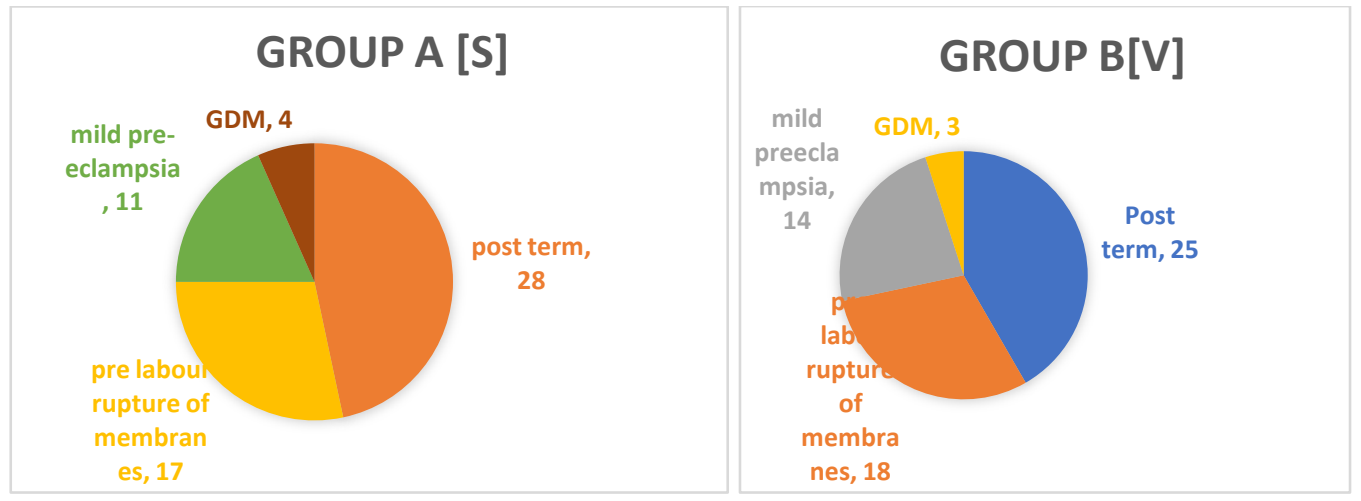

Table 12 Comparison of birth weight of baby [kilograms]

\begin{tabular}{|c|c|c|c|}
\hline & Group A[SLM] & Group B [VM] & P value \\
\hline Baby birth weight [kgs] & $2.89 \pm 0.23$ & $2.90 \pm 0.19$ & 0.83 \\
\hline
\end{tabular}

Table 12 shows mean and standard deviation of There was no significant difference among the baby birth weight [kilograms] in both groups. groups.

\section{Comparision of Birth Weights}

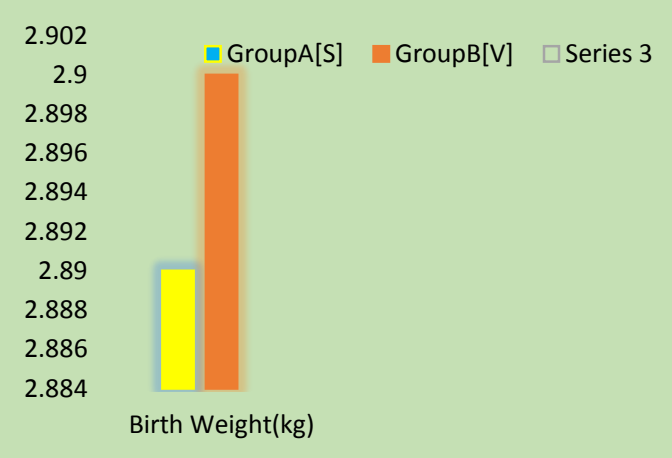




\section{JMSCR Vol||08||Issue||02||Page 124-133||February}

Table 7: Comparison of number of pelvic delivery in $<24$ hours of induction

\begin{tabular}{|l|c|c|c|}
\hline & Group A[S] & Group B [V] & RR [CI 95\%] \\
\hline $\begin{array}{l}\text { Vaginal delivery } \\
<\mathbf{2 4} \text { hours }\end{array}$ & $52[86.7]$ & $50[83.3]$ & $1.04[0.89-1.20]$ \\
\hline
\end{tabular}

Table 6 shows number [percentage] of vaginal no significant difference among the groups. delivery in $<24$ hours in both groups. There was

\section{CHART 6 Vaginal delivery $<24$ hours}

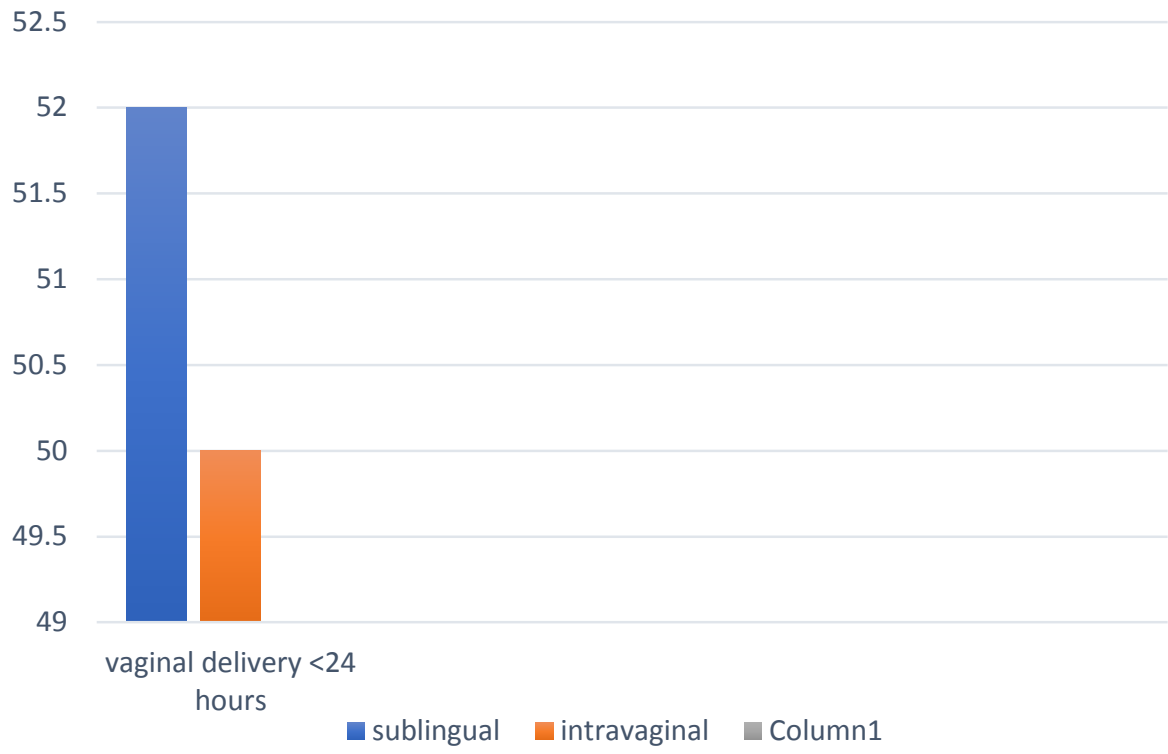

Table 13 Comparison of fetal complications

\begin{tabular}{|c|c|c|c|}
\hline & Group A[SLM] & $\begin{array}{c}\text { Group B } \\
{[\mathbf{V M}]}\end{array}$ & RR [CI 95\%] \\
\hline $\begin{array}{c}\text { Meconium } \\
\text { passage }\end{array}$ & $3[5]$ & $3[5]$ & $1[0.21-4.76]$ \\
\hline $\begin{array}{c}\text { Apgar score } \\
\text { at 5minutes }\end{array}$ & $2[3.3]$ & $2[3.3]$ & $1[0.15-6.87]$ \\
\hline NICU admission & $1[1.6]$ & $2[3.3]$ & $\begin{array}{c}0.5[0.05- \\
5.37]\end{array}$ \\
\hline
\end{tabular}

Table 13 shows number [percentage] of fetal significant difference among the groups. complication in both groups. There was no 
Chart 13 Comparison of foetal complications

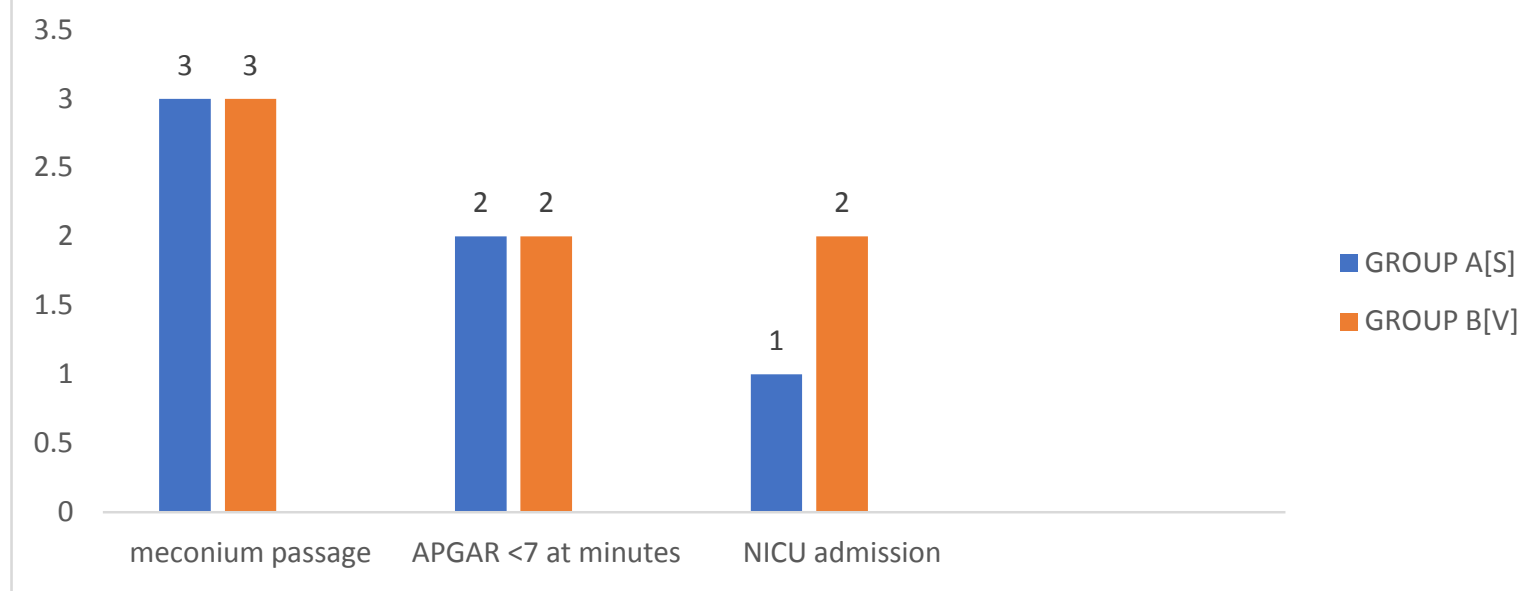

\section{Discussion}

In our study we had included 120 antenatal women by randomization technique.

There was no difference in age, parity, gestational age, bishop score and indication of induction among the both groups in our study. The results had showed that $25 \mu \mathrm{g}$ of sublingual misoprostol administration resulted in significantly shorter induction to delivery interval $[p<0.005]$, with a lower number of misoprostol doses required $[p<0.01]$ and lesser number of pelvic examination $[\mathrm{p}<0.05]$ required as compared with those administered $25 \mu \mathrm{g}$ of vaginal misoprostol.

In present study no statical significant difference was found in age group, parity, induction to delivery interval, which is similar in Jahroni bahia namavar et $\mathrm{al}^{5}$ study (2009-2011), Ayathi et $\mathrm{al}^{6}$ study (2007-2008).

In present study, there is no statistical significant difference in bishop score in both groups. Similar results were observed in jahroni study but In Ayathi etal study, bishop score was found higher in sublingual when compared to vaginal group.

In Tang et al. ${ }^{7}$ study, the sublingual route has been shown to produce significantly higher serum peak concentration of misoprostol than either oral or vaginal administration.

A recently published study evaluated the effects of misoprostol on uterine contractility following different routes of administration ${ }^{10}$. The sublingual application of misoprostol had rapid effect on uterine contractility as oral administration and the bioavailability was similar to vaginal administration. We had administered sublingual dosage every $4^{\text {th }}$ hourly. These findings may explain the significant reduction in induction delivery interval with sublingual misoprostol.

Our study had showed a significant reduction in number of pelvic examination before delivery. Patient would be comfortable when number of pelvic examination was reduced. We had not taken satisfaction parameter in our study as it was beyond our scope.

Nasser et $\mathrm{al}^{11}$ had studied on patient satisfaction criteria and concluded that sublingual misoprostol was convient and satisfactory route. This route of administration may reduce the chance of infection particularly in PROM cases because of less number of vaginal examinations required. On considering these facts and our observation on significant decrease in number of pelvic examination sublingual route may be a satisfactory route of administering misoprostol.

\section{Conclusion}

Sublingual dosing for labour induction is attractive because of ease of administration, less frequent need for vaginal examination, possibility of its use in case of vaginal bleeding or ruptured membranes and better patient acceptability. We believe further studies on safety with large number of women need to be conducted before we 
advocate sublingual misoprostol as routine labour induction agent.

\section{References}

1. Gary, F. Williams Obstetrics. (25 ed.). United States Of America: ; c2014.

2. Dutta, D.C. Text book of obstetrics including contraception and perinatology. (7 th ed.). United States Of America: Hiralal konar; 2013.

3. Hofmeyr GJ. Induction of labour with an unfavourable cervix. Best Pract Res Clin Obstet Gynaecol 2003; 17:777-94.

4. Jahromi BN, Poorgholam F, Yousefi G, Salarian L. Sublingual versus Vaginal Misoprostol for the Induction of Labor at Term: A Randomized, Triple-Blind, Placebo-Controlled Clinical Trial. Iran J Med Sci. 2016;41(2):79-85.

5. Ayati S, Vahidroodsari F, Farshidi F, Shahabian M, Afzal Aghaee M. Vaginal versus sublingual misoprostol for labor induction at term and post term: a randomized prospective study. Iran $J$ Pharm Res. 2014;13(1):299-304.

6. Tang OS, Schweer H, Seyberth HW, Lee SW, Ho PC. Pharmacokinetics of different routes of administration of misoprostol. Human Reproduction 2002; 17:332-6.

7. Aronsson, M. Bygdeman and K. GemzellDanielsson. Human Reproduction 2004; Vol.19 No.1:81-84.

8. Nassar AH, Awwad J, Khalil AM, AbuMusa A, Mehio G, Usta IM. A randomized comparison of patient satisfaction with vaginal and sublingual misoprostol for induction of labour at term. BJOG 2007; 114:1215-21. 